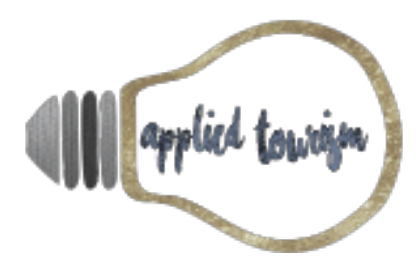

Volume 3, número 3, 2018, p. 01- 12

\title{
INDICADORES DA QUALIDADE DOS SERVIÇOS HOTELEIROS PRESTADOS EM FLORIANÓPOLIS SOB A VISÃO DOS HÓSPEDES
}

\author{
Ícaro Argenta Malheiros \\ Graduando do Curso Superior em Tecnologia de Hotelaria, IFSC \\ icaroargenta@gmail.com \\ Maria Aparecida Gonçalves \\ Graduando do Curso Superior em Tecnologia de Hotelaria, IFSC \\ gomaria15@gmail.com
}

Tânia Regina Egert Petry Mestre em Turismo e Hotelaria, UNIVALI taniaegert@gmail.com

Recebido: 14 de fevereiro, 2018

Aprovado: 27 de março, 2018

\section{RESUMO}

O presente estudo tem como objetivo principal analisar os indicadores da qualidade dos serviços prestados pelos hotéis de Florianópolis por meio do site Booking.com (Booking online, 2017) e a partir dos resultados encontrados comparar as notas das cidades de Florianópolis e de Balneário Camboriú (Bordignon, Araujo, Meira \& Anjos, 2016). A coleta de dados ocorreu no mês de junho de 2017, com análise de 81 hotéis de Florianópolis. Como resultado da pesquisa pôde-se verificar que os indicadores de qualidade dos hotéis de Florianópolis têm uma média razoável, com exceção da localização que conta com uma nota acima da média. Por outro lado, o serviço de internet wi-fi mostrou-se insuficiente para os hóspedes, o que representa um grande desafio, visto o uso significativo de dispositivos móveis nas viagens. Ao comparar os indicadores dos hotéis de Balneário Camboriú e de Florianópolis tem-se que a média geral de Florianópolis se mostra relativamente superior.

Palavras-chaves: Indicadores da qualidade dos serviços. Hotelaria. Florianópolis. 


\section{INTRODUÇÃO}

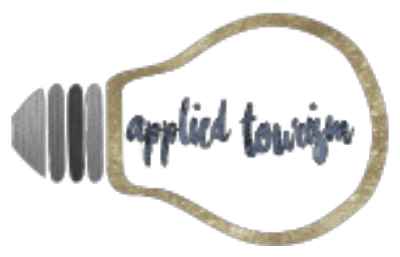

Volume 3, número 3, 2018, p. 01- 12

Florianópolis é a capital do Estado de Santa Catarina (Brasil) e conta com o turismo como grande impulsionador de sua economia. Tendo isso em vista, o presente estudo tem como objetivo principal analisar os principais indicadores da qualidade dos serviços hoteleiros prestados pelos hotéis de Florianópolis por meio do site Booking.com (Booking online, 2017) e a partir dos resultados encontrados comparar as notas das cidades de Florianópolis e de Balneário Camboriú (Bordignon, Araujo, Meira \& Anjos, 2016).

Segundo Hoffman \& Bateson (2003, p. 3) "os serviços estão em toda a parte: em uma viagem para um destino exótico, uma consulta médica, um serviço de igreja, uma ida ao banco [...]".

Tratando especificamente da qualidade dos serviços hoteleiros, o primeiro fator a ser levado em conta são os serviços básicos, como por exemplo, segurança e higiene, mas existem outros como internet sem fio gratuita, conforto, localização e custo benefício que influenciam sobretudo a percepção da qualidade dos serviços dos hóspedes. Tendo isso em vista, foram selecionados neste estudo os seguintes serviços de qualidade categorizados no site booking.com: limpeza, conforto, localização, comodidades, funcionários, custo benefícios e wi-fi gratuito (internet sem fio).

Com a verificação destes dados será possível fazer uma análise dos melhores e piores indicadores de qualidade dos hotéis indicados pelos hóspedes e de comparar os indicadores de Florianópolis (SC) com os indicadores de outras cidades, como de Balneário Camboriú (SC).

Para tanto, a presente pesquisa pretende responder ao seguinte problema de pesquisa: quais são os indicadores da qualidade dos serviços hoteleiros prestados pelos hotéis de Florianópolis (SC) comparativamente a hotelaria de Balneário Camboriú?

\section{FUNDAMENTAÇÃO TEÓRICA}

Serviços são ações, esforços ou desempenho. Para Hoffman \& Bateson (2003, p. 9) "devido à intangibilidade dos serviços, os clientes muitas vezes têm dificuldades para avaliar a qualidade de serviços de forma objetiva". Parasuraman, Zeithaml \& Berry (1988, p. 13) destacam três pontos fundamentais como características dos serviços: 


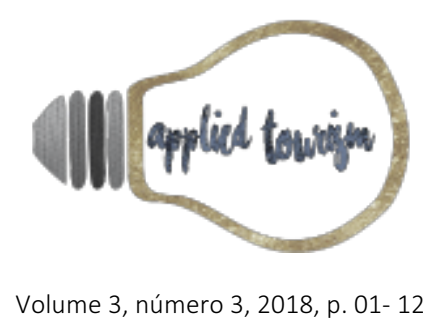

- Simultaneidade: serviços são consumidos quase que simultaneamente ao momento em que são produzidos, tornando difícil ou quase impossível detectar e corrigir as falhas antes que elas ocorram e afetem o cliente

- Intangibilidade: os serviços representam um produto não físico, ou seja, não podendo ser transportados e/ou armazenados;

- Heterogeneidade: a grande variedade de serviços existentes e o forte relacionamento com o fator humano dificultam a atividade de padronização e estimação de preços. Curiosamente, de acordo com o serviço que está adquirindo, o cliente poderá receber diversas denominações, dentre as quais: consumidor, freguês, usuário, hóspede, paciente, requisitante, etc.

Especificamente no turismo, Swarbrooke \& Horner (2007) destacam algumas particularidas inerentes ao produto/serviço turístico, que o diferem de outras experiências de compra, a citar como exemplo: o envolvimento e compromisso do consumidor na escolha, a insegurança relacionada à intangibilidade do produto, a presença de fatores emocionais, a influência de outras pessoas, as decisões de longo prazo a serem tomadas, bem como a extensa busca de informações sobre o produto a ser adquirido.

Por todas estas circunstâncias, é muito mais provável que a experiência de pagar por uma viagem, que compromete parte considerável da renda do consumidor, seja mais cuidadosa e seletiva do que a compra de outros produtos, como os de gênero alimentício por exemplo. Sua complexidade dá-se pelo fato do produto turístico ser uma experiência integral, não um produto claramente definido.

Segundo Ruschmann (2000), por meio do movimento turístico as pessoas satisfazem necessidades e desejos de cultura, status, lazer, curiosidade, bem-estar, entre outros, diferentemente daqueles determinados pelo seu cotidiano.

Nesta perspectiva, com um melhor entendimento a respeito do produto/serviço turístico, na sequência a pesquisa irá abordar os seguintes tópicos: Qualidade dos serviços hoteleiros; e Indicadores de qualidade e Influências das tecnologias. 


\section{QUALIDADE DOS SERVIÇOS HOTELEIROS}

Consideram-se meios de hospedagem os empreendimentos ou estabelecimentos, independentemente de sua forma de constituição, destinados a prestar serviços de alojamento temporário, ofertados em unidades de frequência individual e de uso exclusivo do hóspede, bem como outros serviços necessários aos usuários, denominados de serviços de hospedagem, mediante adoção de instrumento contratual, tácito ou expresso, e cobrança de diária (Brasil, Lei 11.771/2008 - Art. 23). O Hotel tem a seguinte classificação, pelo Ministério do Turismo (Mtur, 2018): estabelecimento com serviço de recepção, alojamento temporário, com ou sem alimentação, com oferta de unidades individuais e de uso exclusivo dos hóspedes, mediante a cobrança de diária.

A qualidade dos serviços hoteleiros se dá através de opiniões de hóspedes, sendo elas, hoje em dia, em grande parte de forma online.

Figura 01: Ciclo de serviços e momentos da verdade nos meios de hospedagem

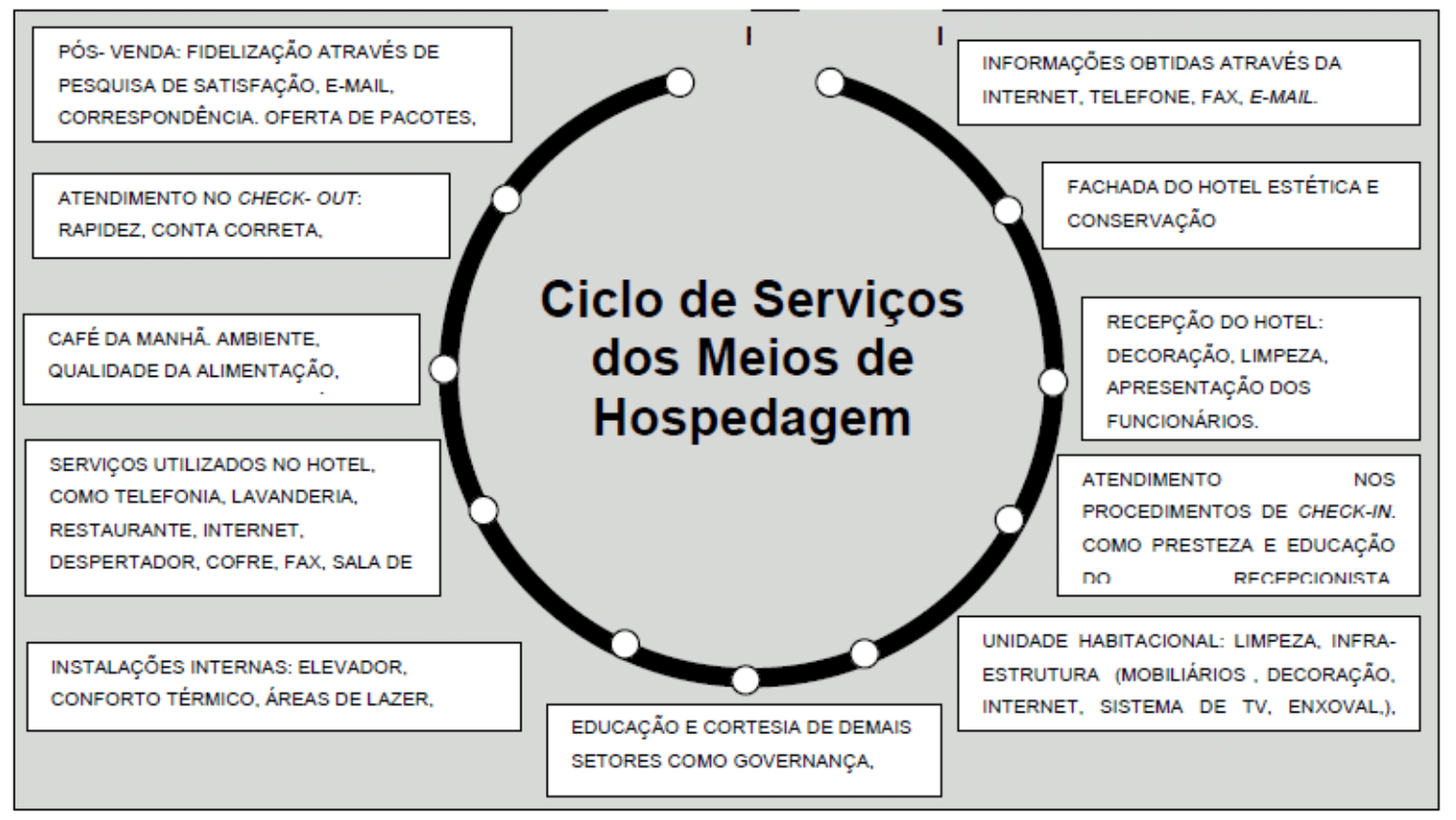

Fonte: Almeida \& Freitas (2012, p. 46)

A partir da Figura 1, verifica-se que a primeira coisa que o hóspede olha quando está procurando um hotel, através do site Booking.com, são as informações e os comentários de avaliação daqueles que já se hospedaram para saber se o hotel é um bom local ou não. Já no hotel, esse hóspede irá avaliar a estrutura como um todo, 


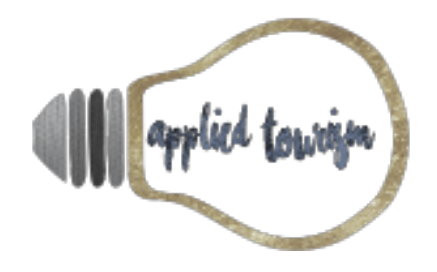

Volume 3, número 3, 2018, p. 01- 12

como por exemplo, a estética e a conservação, também irá prestar atenção no atendimento, na educação dos funcionários, nos serviços que lhe são prestados e no fim, irá fazer uma avaliação daquilo que vivenciou, compartilhando online suas percepções para que o próximo hóspede tenha mais informações.

Nesta perspectiva, Browning, So \& Sparks (2013) e Limberger, Meira \& Añaña (2016) trazem em suas pesquisas no âmbito da hotelaria, que os consumidores estão mais propensos a fazer comentários positivos sobre um conjunto de serviços, do que somente sobre os serviços desempenhados pelos funcionários. Porém, esses comentários dos serviços hoteleiros, acabam impactando também na hora que os outros hóspedes escolhem seu destino turístico. (González; Gidumal \& Valcarcel, 2013).

Quiroga, Mondo \& de Castro Júnior (2014) e Petry, Pickler \& Tomelin (2016) constataram que ao verificar as opiniões on-line, é possível compreender os pontos fortes e fracos dos meios de hospedagem utilizados pelos hóspedes, assim, tendo uma resposta da qualidade dos serviços prestados.

$\mathrm{Na}$ pesquisa realizada por Petry (2016), a expressividade da internet como canal de negociação e consequentemente compra de serviços ligados ao turismo ficou evidenciada, com a maior parte dos consumidores residentes em Santa Catarina fazendo suas reservas por conta própria, sem intermediários. A negociação realizada diretamente com hotéis e empresas de transporte através da internet, telefone ou presencialmente somou $76,8 \%$ do total de respostas obtidas, contra 23,2\% dos que compraram via agência de turismo.

Para as empresas com atuação na área, cabe uma análise de seus modelos de atuação e distribuição, tendo em vista a realidade desses consumidores que utilizaram em sua maioria a internet para negociar o conjunto de atividades turísticas da sua última viagem. Fatores favoráveis e desfavoráveis relacionados à compra, a aprovação e desaprovação de pessoas próximas ao consumidor, além das facilidades e dificuldades encontradas na compra podem ser indicadores a ser melhor trabalhados pelas mesmas.

Gândara, Brea \& Manosso (2013) ressaltam a importância de os hotéis monitorarem os depoimentos on-line, sejam eles sites próprios ou sites que fazem parte da Online Travel Review (OTR), de forma que possam melhorar os serviços oferecidos. Como o Booking.com, por exemplo, que faz parte da OTR, em que os usuários podem avaliar e comentar sobre o hotel, depois de sua estadia (Xiang \& Gretzel, 2010). 


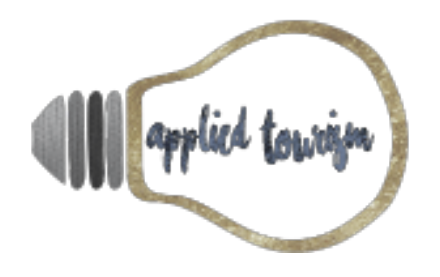

Volume 3, número 3, 2018, p. 01- 12

\section{INDICADORES DE QUALIDADE E INFLUÊNCIA DAS TECNOLOGIAS}

A escala SERVQUAL, é um dos muitos instrumentos que são possíveis de ser utilizados pelos hotéis para avaliar a qualidade dos serviços que são prestados. Criada por Parasuraman, Zeithaml \& Berry (1988), a escala serve para mensurar o grau de satisfação do hóspede no Meio de Hospedagem, em comparação com o grau de expectativa. A escala avalia os pontos fortes e fracos de cinco dimensões fundamentais para a influência dos clientes em relação a avaliação dos serviços: tangibilidade, confiabilidade, capacidade de resposta, segurança e empatia.

Com o avanço das tecnologias dentro dos hotéis, os gestores conseguem otimizar os serviços prestados em seus empreendimentos, focando na internet. É de conhecimento geral que atualmente todos vivem conectados. Dessa forma, ficar sem internet pode ser o fim do mundo para muitas pessoas, e num hotel onde os clientes ficam hospedados em diversas situações por grandes períodos de tempo, a internet tem que ser eficaz, para que assim o cliente se sinta confortável e inserido dentro de seu mundo social dentro da internet.

No entanto, ter uma internet de qualidade dentro dos seus espaços não é tarefa tão simples para o hotel, que relata que o serviço da operadora tem um valor alto para contratação. Além disso, se instalado de forma errada pode causar congestionamento de rota, que seria o caso de muitas pessoas usando o mesmo sinal de wi-fi. O gestor do hotel então, deve consultar o melhor serviço de internet disponível e que tenha a melhor qualidade dentro do custo benefício pretendido. Realizar manutenções com uma frequência mensal na sua rede de internet também pode prevenir incidentes indesejáveis para o hotel.

\section{METODOLOGIA}

O presente artigo fez inicialmente uma análise de conteúdo, que segundo Triviños (1987), pode ser feita da seguinte forma: pré-análise (organização do material), descrição analítica dos dados (codificação, classificação, categorização) e interpretação referencial (tratamento e reflexão).

A escolha de Florianópolis (SC) como objeto de estudo se deve ao fato de o destino ser capital de Santa Catarina e também por estar acima da média nacional com relação ao índice de competitividade do turismo (Mtur, 2015). Outro motivo para a escolha de Florianópolis (SC) foi o interesse por comparar os dados obtidos com pesquisa anterior realizada em Balneário Camboriú (Bordignon, Araujo, Meira \& Anjos, 2016). 


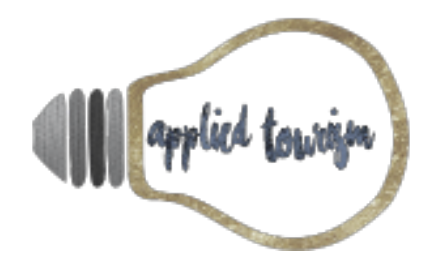

Volume 3, número 3, 2018, p. 01- 12

A coleta de dados foi realizada no site Booking.com no mês de junho de 2017. Os dados foram coletados a partir das 45.563 avaliações dos hóspedes dos 81 hotéis (com avaliações) cadastrados no site. No site do Booking.com, cada hóspede pode avaliar os indicadores de qualidade em uma escala de 1 a 10 pontos, e assim deixar sua avaliação de como foi a sua experiência durante a estadia. Os indicadores de qualidade analisados foram: avaliação geral, conforto, limpeza, localização, comodidades, funcionários, custo benefício e wifi-grátis. É importante ressaltar que nem todos os hotéis contam com serviço de wifi-grátis. A análise foi feita gerando a média dos indicadores de qualidade em relação aos hotéis avaliados.

Após a coleta realizou-se uma comparação com os dados já coletados na pesquisa realizada em Balneário Camboriú para a verificação de quais indicadores de qualidade são mais divergentes em relação a nota, investigando-se as razões desta diferença.

\section{RESULTADOS E DISCUSSÕES}

Conforme pode ser visualizado no Quadro 01, por meio do estudo realizado verificaram-se os seguintes dados sobre os indicadores de qualidade dos hotéis de Florianópolis.

Quadro 01: Análise dos indicadores de qualidade dos serviços dos hotéis de Florianópolis (SC)

\begin{tabular}{|c|c|}
\hline Nota média geral & 7,9407 \\
\hline Limpeza & 7,9827 \\
\hline Conforto & 7,6444 \\
\hline Localização & 8,4629 \\
\hline Comodidades & 7,6024 \\
\hline Funcionários & 8,2987 \\
\hline Custo benefício & 7,6641 \\
\hline$W i-F i$ & 7,1580 \\
\hline
\end{tabular}

Fonte: Booking online (2017)

Analisando inicialmente os indicadores de qualidade totais, observa-se que a nota média ficou em 7,94. A nota tem um resultado favorável, porém poderia estar maior, pois estes hotéis estão localizados na capital do Estado de Santa Catarina, referência para o turismo em âmbito brasileiro. 


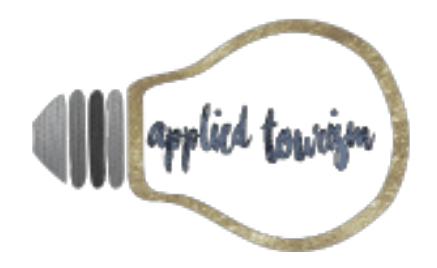

Volume 3, número 3, 2018, p. 01- 12

Quadro 02: Análise dos indicadores de qualidade dos serviços dos hotéis de Balneário Camboriú (SC)

\begin{tabular}{|c|c|}
\hline Nota média geral & 7,798 \\
\hline Limpeza & 7,856 \\
\hline Conforto & 7,398 \\
\hline Localização & 8,564 \\
\hline Comodidades & 7,386 \\
\hline Funcionários & 8,094 \\
\hline Custo benefício & 7,464 \\
\hline Wi-Fi & 6,704 \\
\hline
\end{tabular}

Fonte: Bordignon, Araujo, Meira \& Anjos (2016)

Fazendo a comparação da avaliação geral dos hotéis de Florianópolis com os hotéis de Balneário Camboriú, observa-se que Florianópolis encontra-se com 0,142 pontos a frente de Balneário Camboriú, com média 7,798.

Partindo para o indicador de limpeza, Florianópolis fica com 7,982 enquanto Balneário Camboriú consta com 7,856, mostrando uma pequena variação entre os dois destinos. A nota tem um resultado satisfatório e está relacionada com a média geral, o que denota que os hotéis deveriam tomar mais cuidado com a limpeza, pois se trata tanto de uma questão de beleza do hotel quanto de bons modos com os clientes e até a higiene local.

Uma hipótese para que o hotel atinja melhor nota no seu indicador de qualidade é que contrate, empresas que ofereçam o serviço de limpeza e camareiras voltadas para hoteis, que já tenham renome com o trabalho dentro de hoteis. E a aplicação de um funcinário que faça a revisão de cada quarto após a limpeza de cada, profissão conhecida como supervisora de andar.

No indicador de conforto, Florianópolis fica com nota média de 7,644, nota que se mostra razoável quando comparada a Balneário Camboriú, com 7,398. Neste indicador Florianópolis se destaca, porém, apesar de ambos indicadores serem razoáveis, uma iniciativa poderia ser tomada por parte dos hotéis, pois o conforto é muito importante para que o hóspede se sinta acomodado pelo hotel e queira voltar novamente.

O indicador de localização é o que mais se destaca em ambas as cidades, contando com a nota média de 8,462 em Florianópolis e em Balneário Camboriú 8,564. Ambos indicadores estão acima da média geral de suas regiões, o que mostra que a localização dos hotéis é bastante favorável. Neste indicador Balneário tem 0,1 pontos a mais mesmo tento uma nota média geral menor, o que denota que a localização dos hotéis de Balneário Camboriú é melhor que de Florianópolis. 


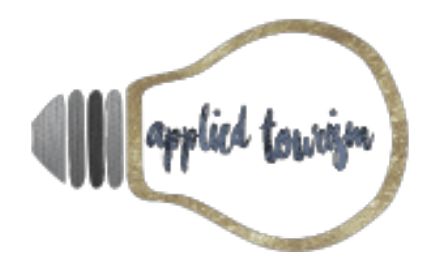

Volume 3, número 3, 2018, p. 01- 12

O indicador de comodidades fica com nota média de 7,602 em Florianópolis, o que é uma nota razoável, visto que está 0,3 pontos a menos que a média geral. Já em Balneário Camboriú a nota média é inferior, com 7,381. Ambos hotéis têm a comodidade com nota razoável abaixo da média geral. Uma alternativa é de que os hotéis pesquisem qual os indicadores de comodidade qua mais satisfazem os hóspedes durante a estada. Assim o hotel pode aplicar os produtos de comodidade, como móveis e decoração, que mais agradem os hóspedes, afim de ter um aumento na nota e assim chame a atenção de quem procura por hotéis na região, ao mesmo tempo que fideliza os hóspedes que passaram pelo hotel.

No indicador funcionários a nota média em Florianópolis ficou em 8,298, uma nota agradável e acima da média, o que nos indica que os funcionários em Florianópolis atendem bem seus clientes. Neste indicador denota avaliação melhor que Balneário Camboriú, com média 8,094.

Com relação ao custo benefício Florianópolis ficou com nota 7,664, o que mostra que os hotéis de Florianópolis não são tão econômicos. Em Balneário Camboriú a nota média é de 7,464, nota inferior a de Florianópolis, o que indica que Florianópolis mesmo tendo um custo benefício razoável, pode atrair melhor os turistas que pretendem economizar, em comparação a Balneário Camboriú.

No indicador de qualidade wi-fi Florianópolis fica com nota média de 7,158 e Balneário Camboriú com 6,704. Estas notas estão abaixo da média geral e são preocupantes, visto a importância da internet nos dias atuais. Os hotéis deveriam se preocupar mais com o serviço de internet. Um relativamente novo, porém os hotéis têm de se manter sempre atualizados. Muitos hóspedes atualmente dão valor a internet, querem chegar no seu cômodo e entrar em suas redes sociais, ou então ver um vídeo. Neste caso, se a internet do hotel não for boa, isso causará um grande desconforto no hóspede.

Uma hipótese é que os hotéis façam contratos combinados com mais de uma provedora de internet assim, caso uma deixe de funcionar o hotel não será refém de um único serviço. É importante também consultar as novas tendências da tecnologia, como a fibra ótica, que tem um alto custo de instalação, porém proporciona mais velocidade de navegação para os hóspedes que optem pelo o uso de cabo de internet. O uso de um roteador de dedicado a antenas de wi-fi dual band $(2.4 \mathrm{Ghz}-5.8 \mathrm{Ghz})$ otimiza o serviço de internet sem fio para todas as regiões do hotel. 


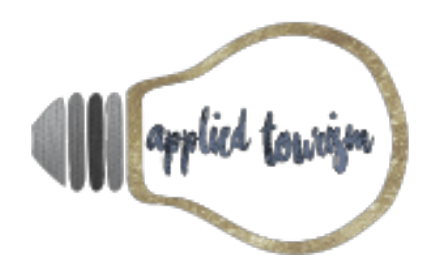

Volume 3, número 3, 2018, p. 01- 12

Deste modo, analisando cada indicador de qualidade é possível afirmar que os hotéis de Florianópolis possuem qualidade em seus serviços, mas que os mesmos poderiam ser melhorados. Com a comparação entre Balneário Camboriú e Florianópolis pode-se observar que Florianópolis tem seus serviços um pouco mais bem avaliados pelos hóspedes, mas não foge muito da média. Ao observar as avaliações de ambos os hotéis verifica-se que a localização e a internet wi-fi obtiveram respectivamente o melhor e o pior indicador de qualidade.

\section{CONSIDERAÇÕES FINAIS}

Através deste estudo foi possível constatar que os hotéis analisados precisam reverter seu problema com o seu serviço de wi-fi. A partir destas dificuldades apontadas pelos hóspedes, é possível verificar grandes riscos aos hotéis, visto que atualmente o mundo gira entorno da internet. Também é de grande valor ressaltar como a localização dos hotéis de ambas cidades é vantajosa, contando com uma nota bem acima da média geral.

A média geral dos hotéis é bem parecida, no entanto Florianópolis apresentou melhor colocação que Balneário Camboriú, com nota de 7,940 enquanto que Balneário Camboriú ficou com 7,798. Isso mostra que a região tem um turismo de qualidade, porém é importante destacar que essas notas poderiam subir mais, levando em conta que as cidades analisadas são destinos de referência do turismo de Santa Catarina.

Para que esses dados sejam melhor analisados e comparados, seria importante que outras cidades que são referência no turismo também tivessem seus dados coletados, para que assim fosse feito uma análise com âmbito maior de abrangência.

\section{REFERÊNCIAS}

Almeida, G. M. M., Freitas, A. L. P. (2012). Meios de hospedagem: a qualidade na visão do cliente. Curitiba: Appris.

Booking, online. (2017). Disponível em http://www.booking.com

Bordignon, L. F., Araujo, J. V. N., Meira, J. V. De S., \& Anjos, S. J. G. dos. (2016). Principais indicadores da qualidade dos serviços em hotéis de Balneário Camboriú (SC) na visão dos hóspedes. Fórum científico de turismo, gastronomia e hotelaria (FCGTURH). Balneário Camboriú. Anais/Universidade do Vale do Itajaí (UNIVALI).

Brasil. (2008). Lei no 11.771, de 17 de setembro de 2008. Dispõe sobre a Política Nacional de Turismo, define as atribuições do Governo Federal no planejamento, desenvolvimento e estímulo ao setor turístico; revoga a Lei $n^{\circ} 6.505$, de 13 de dezembro de 1977, o DecretoLei $n^{\circ}$ 2.294, de 21 de novembro de 1986, e dispositivos da Lei $n-0.181$, de 28 de março 


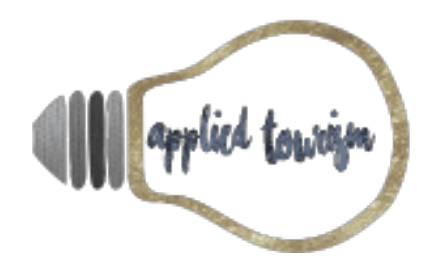

Volume 3, número 3, 2018, p. 01- 12

de 1991; e dá outras providências. Diário oficial da República Federativa do Brasil. Brasília, DF, 18 set. 2008.

Browning, V., So, K. K. F., \& Sparks, B. (2013). The influence of online reviews on consumers' attributions of service quality and control for service standards in hotels. Journal of Travel \& Tourism Marketing, 30, 23-40.

Gándara, J. M. G., Fraiz Brea, J. A., \& Manosso, F. C. (2013). Calidad de la experiencia en los hoteles termales de Galicia, España: un análisis a través de la reputación online. Estudios y perspectivas en turismo, 22(3), 492-525.

González, S. M., Gidumal, J. B., \& Valcarcel, B. G. L. (2013). Online customer reviews of hotels: As participation increases, better evaluation is obtained. Cornell Hospitality Quarterly, 54(03), 274-283.

Hoffman, K. D., \& Bateson, J. E. G. (2003). Princípios de marketing de serviços: conceitos estratégias e casos. São Paulo: Pioneira Thomson Learning.

Limberger, P. F., Meira, J. V. de. S., \& Anãña, E. da S. (2016). A qualidade dos serviços na hotelaria: um estudo com base nas on-line travel reviews (ORTS). Revista Turismo - Visão e Ação - Eletrônica, v. 18, n. 3.

Ministério do Turismo. (2015). Índice de Competitividade do Turismo Nacional: Florianópolis 2015.

http://www.turismo.gov.br/sites/default/turismo/o_ministerio/publicacoes/Indice_com petitividade/2015/Florianopolis_RA_2015.pdf

Ministério do Turismo. (2018). Sistema brasileiro de classificação de meios de hospedagem (Sbclass). Disponível em: http://www.turismo.gov.br/acesso-a-informacao/63-acoes-eprogramas/5021-sistemabrasileiro-de-classificacao-de-meios-de-hospedagemsbclass.html

Parasuraman, A., Zeithaml, V. A., \& Berry, L. L. (1988). SERVQUAL: A multiple-item scale for measuring consumer perceptions of service quality. Journal of Retailing, vol. 64, no 1, pp. $12-40$.

Petry, T. R. E. (2016). Intenção Comportamental de Compra de Viagens e Turismo: uma aplicação do modelo teórico da Teoria do Comportamento Planejado com os consumidores de Santa Catarina, Brasil. Balneário Camboriú: UNIVALI, 2016. 168F. Dissertação (Mestrado em Turismo e Hotelaria) - Programa de pós-graduação em Turismo e Hotelaria, Universidade do Vale do Itajaí, Balneário Camboriú, 2016.

Petry, T. R. E., Pickler, C de M., \& Tomelin, C. A. (2016). A percepção dos hóspedes de negócios quanto ao desempenho da qualidade dos serviços prestados nos hotéis de Florianópolis: uma análise a partir do conteúdo gerado no website Booking.com. Revista Turismo - Visão e Ação - Eletrônica, v. 18, n. 2.

Quiroga, R. M., Mondo, T. S., \& De Castro Júnior, D. F. L. (2014). Reputação online como instrumento para melhoria de serviços: um estudo na hotelaria de Garopaba e Imbituba - Santa Catarina. Revista de Turismo Contemporâneo, v. 2, n. 1.

Ruschmann, D. (2000) Marketing turístico: um enfoque promocional. Campinas: Papirus. 


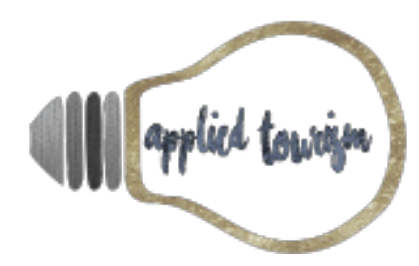

Volume 3, número 3, 2018, p. 01- 12

Swarbrooke, J., \& Horner, S. (2007). Consumer behaviour in tourism. 2 ed. New York, NY: Routledge.

Triviños, A. N. S. (1987). Introdução à pesquisa em ciências sociais: a pesquisa qualitativa em educação. São Paulo: Atlas.

Xiang, Z. \& Gretzel, U. (2010). Role of social media in online travel information search . Tourism Management, 31, 179-188. 